\title{
Prediction of body density from skinfold measurements
} in lactating women

\author{
BY NANCY F. BUTTE, CATHY WILLS, E. O'BRIAN SMITH \\ AND CUTBERTO GARZA \\ USDA/ARS Children's Nutrition Research Center, Department of Pediatrics, \\ Baylor College of Medicine, Texas Children's Hospital, \\ Houston, TX 77030, USA
}

(Received 1 May 1984 - Accepted 13 December 1984)

1. Regression equations predicting body density from skinfold measurements were derived for a group of lactating women.

2. It was concluded that specific equations for lactation were not necessary, since the resultant equations were not significantly different from those published for non-lactating women.

3. The ability to predict an individual's body density from skinfold thickness measurements was unsatisfactory for either clinical or research applications.

Skinfold thickness has been shown to be negatively correlated with body density. Regression equations which predict body density from skinfold thickness have been used to calculate body fat of adult men and women (Sloan et al. 1962; Young et al. 1962; Durnin \& Rahaman, 1967; Katch \& Michael, 1968; Wilmore \& Behnke, 1970; Durnin \& Womersley, 1974; Pollock et al. 1975; Ward et al. 1975) at different ages. Maximum accuracy is attained when prediction equations are derived from samples of the population to which they will be applied. Differences in the published equations defined for specific age and sex groupings have been attributed to changes in fat distribution, skinfold compressibility and the density of fat-free mass. Since the distribution of subcutaneous fat undergoes significant changes in the pregnant and lactating female, the applicability of available equations has been questioned. The density of the fat-free mass may change during pregnancy; however, pregnant women do not store high-density materials (non-fat solids) in excess of those accounted for by the products of conception, increase in the size of the reproductive organs and increased blood volume (Seitchik et al. 1963). Approximately $4 \mathrm{~kg}$ fat are laid down during a normal pregnancy (Hytten \& Leitch, 1971). This fat is not distributed uniformly, but preferentially over the thighs, abdomen and back (Taggart et al. 1967). In addition, the metabolism and mobilization of adipose tissue changes during lactation (Poo et al. 1939; Flint et al. 1980). Predictive equations derived from pregnant and lactating women have not been published.

In the present study, the relation between body density and skinfold thickness was investigated in a group of lactating women. Resultant regression equations were compared with those of Durnin \& Womersley (1974). Although derived equations were not significantly different from those of Durnin \& Womersley (1974), in both cases the ability to predict an individual's body density from skinfold measurements was poor.

\section{MATERIALS AND METHODS}

Anthropometric and densitometric measurements on forty-five lactating women, mean age $28 \cdot 0$ (SD 3.1) years (range 21-36 years), were performed at months $1,2,3$ and 4 post partum. Ethnic background was distributed as follows: forty-one Caucasian, two Hispanic, one 
Asian and one West Indian. The sample population and study design have been described fully in a previous publication (Butte et al. 1984).

Skinfold thicknesses were measured to the nearest $0.5 \mathrm{~mm}$ using Lange calipers at the following sites: triceps, biceps, suprailiac and subscapular (Durnin \& Rahaman, 1967). These measurements were made generally by one person. Maternal weight was measured on a beam balance and height was measured with an upright extension meter.

Body density was derived from water displacement measurements in a Whitmore Volumeter (San Antonio, TX). Residual lung volume was estimated by a modification of the standard oxygen-dilution technique (Wilmore et al. 1980). Gastrointestinal gases were approximated to be $100 \mathrm{ml}$. Body fat was calculated according to Siri (1956).

Statistical analysis (Ryan et al. 1981) included the calculations of means and standard deviations, and correlation matrices of the anthropometric and densitometric variables. Trends over time were tested by fitting polynomial regressions to individuals. Linear regression was used to generate prediction equations. Differences in slopes and intercepts of regression equations were tested by repeated measures of analysis of covariance. McNemar's test was used to compare classification of individuals by two methods (Glantz, 1981).

\section{RESULTS}

The anthropometric and densitometric measurements are shown in Table 1. Triceps and biceps skinfold thicknesses did not change significantly over the 4 months. Measurements of the suprailiac and subscapular skinfolds $(P<0.001)$ and the sum of all sites $(P<0.002)$ decreased significantly over time. Skinfold measurements at the various sites were correlated significantly $(r$ ranged from 0.50 to $0.77, P<0.01)$ with body density; the suprailiac site was the single highest correlate, on a par with the sum of the skinfolds ( $r$ ranged from 0.64 to $0 \cdot 78, P<0 \cdot 01$ ). Significant intercorrelations between skinfold sites were observed $(P<0 \cdot 01)$. The distribution of the sums of the skinfold thicknesses in the present study were non-normal, therefore a logarithmic transformation of the sum of the skinfold thicknesses at each month was performed to normalize and linearize the data.

The linear regression equations for the estimation of body density from the logarithm of the sum of skinfold thicknesses are shown in Table 2 for each of the 4 months of observation. Highly significant linear correlations were demonstrated at each month $(P<0.001)$. No significant differences between the slopes could be detected between the four lines, although the intercepts were different $(P<0.05)$. On average, $54 \%$ of the variability seen in body density was explained by the log of the sum of skinfold thicknesses.

The four regression equations were compared with the equation published by Durnin \& Womersley (1974) for non-pregnant, non-lactating females aged 20-29 years (Table 2). A $t$ test of the slopes and intercepts did not detect significant differences between our equations and the equation of Durnin \& Womersley (1974).

The $95 \%$ confidence and prediction intervals calculated at the mean from the respective sets of values are presented in Table 3 . The average confidence interval of \pm 0.0032 units translates into $\pm 1.5 \%$ body fat and the average prediction interval of \pm 0.0215 units represents $\pm 10 \%$ body fat. Analogous calculations using the values from Durnin \& Womersley (1974) resulted in similar intervals.

Body fat predicted from our four regression equations and from the equation of Durnin \& Womersley (1974) was used to classify the forty-five subjects into three arbitrary categories of body fat: $<15 \%, 15-30 \%,>30 \%$. Predicted body fat derived from our equations correctly categorized $67,58,73$ and $73 \%$ of the subjects for months $1,2,3$ and 4 respectively. Application of the equation of Durnin \& Womersley (1974) resulted in appropriate classification in $64,56,68$ and $58 \%$ of the cases over the same 4 months. The 
Table 1. Anthropometric measurements of forty-five lactating women at months $1,2,3$ and 4 post partum

(Mean values and standard deviations)

\begin{tabular}{|c|c|c|c|c|c|c|c|c|}
\hline \multirow[t]{2}{*}{ Month post partum... } & \multicolumn{2}{|c|}{1} & \multicolumn{2}{|c|}{2} & \multicolumn{2}{|c|}{3} & \multicolumn{2}{|c|}{4} \\
\hline & Mean & SD & Mean & SD & Mean & SD & Mean & SD \\
\hline Height (m) & 1.63 & 0.063 & $1 \cdot 63$ & 0.063 & $1 \cdot 63$ & 0.063 & 1.63 & 0.063 \\
\hline $\mathbf{W t}(\mathbf{k g})$ & $61 \cdot 3$ & $9 \cdot 5$ & $60 \cdot 7$ & $10 \cdot 0$ & $60 \cdot 2$ & $10 \cdot 4$ & $59 \cdot 3$ & $10 \cdot 5$ \\
\hline Triceps (mm) & 16.9 & $4 \cdot 6$ & $17 \cdot 0$ & $4 \cdot 7$ & $17 \cdot 3$ & $5 \cdot 3$ & $17 \cdot 2$ & $5 \cdot 2$ \\
\hline Subscapular (mm) & 16.8 & $6 \cdot 4$ & $16 \cdot 4$ & $7 \cdot 4$ & $15 \cdot 7$ & $7 \cdot 2$ & $15 \cdot 1$ & $7 \cdot 3$ \\
\hline Biceps (mm) & $6 \cdot 9$ & $3 \cdot 2$ & 6.9 & $3 \cdot 3$ & $7 \cdot 3$ & $4 \cdot 6$ & $6 \cdot 8$ & $3 \cdot 4$ \\
\hline Suprailiac (mm) & $25 \cdot 7$ & $6 \cdot 9$ & $25 \cdot 2$ & $7 \cdot 6$ & $23 \cdot 1$ & $8 \cdot 1$ & $22 \cdot 2$ & $8 \cdot 0$ \\
\hline Sum skinfolds (mm) & $66 \cdot 3$ & $18 \cdot 9$ & $65 \cdot 5$ & $20 \cdot 6$ & $63 \cdot 4$ & $22 \cdot 9$ & $61 \cdot 7$ & $21 \cdot 8$ \\
\hline Body density $\times 10^{3}\left(\mathrm{~kg} / \mathrm{m}^{3}\right) \dagger$ & 1.036 & 0.016 & 1.038 & 0.014 & 1.039 & 0.016 & $1 \cdot 040$ & $0 \cdot 016$ \\
\hline Body fat (\% body-weight) $\dagger$ & $28 \cdot 0$ & $7 \cdot 4$ & $27 \cdot 2$ & $6 \cdot 3$ & $26 \cdot 3$ & $6 \cdot 8$ & $26 \cdot 3$ & $7 \cdot 6$ \\
\hline
\end{tabular}

$\dagger$ From densitometric measurements.

Table 2. Linear regression equations for the estimation of body density from skinfold thickness

( $Y$ is density $\times 10^{3}\left(\mathrm{~kg} / \mathrm{m}^{3}\right)$ and $X$ is logarithm of the sum of the skinfold thicknesses at the triceps, biceps, suprailiac and subscapular sites)

\begin{tabular}{ccccc}
\hline Month post partum & Linear equation & $r$ & $R^{2}$ & SD of $Y$ \\
\hline 1 & $Y=1.1889-0.0851 X$ & 0.71 & 0.51 & 0.01143 \\
2 & $Y=1.1671-0.0719 X$ & 0.67 & 0.45 & 0.01034 \\
3 & $Y=1.1710-0.0744 X$ & 0.76 & 0.58 & 0.01021 \\
4 & $Y=1.1854-0.0826 X$ & 0.80 & 0.64 & 0.01001 \\
Durnin \& Womersley (1974) & $Y=1.1599-0.0717 X$ & - & - & 0.0109 \\
\hline
\end{tabular}

Table $3.95 \%$ confidence and prediction intervals calculated at the mean for body density and body fat

\begin{tabular}{|c|c|c|c|c|c|c|}
\hline \multirow[b]{2}{*}{ Month post partum } & \multicolumn{3}{|c|}{ Density $\times 10^{3}\left(\mathrm{~kg} / \mathrm{m}^{3}\right)$} & \multicolumn{3}{|c|}{ Body fat $(\%$ body-wt)* } \\
\hline & Mean & $\begin{array}{c}95 \% \\
\text { Confidence }\end{array}$ & $\begin{array}{c}95 \% \\
\text { Prediction }\end{array}$ & Mean & $\begin{array}{c}95 \% \\
\text { Confidence }\end{array}$ & $\begin{array}{c}95 \% \\
\text { Prediction }\end{array}$ \\
\hline 1 & $1 \cdot 0357$ & \pm 0.0036 & \pm 0.0234 & $27 \cdot 94$ & $26 \cdot 28-29 \cdot 60$ & $17 \cdot 38-38 \cdot 99$ \\
\hline 2 & $1 \cdot 0375$ & \pm 0.0032 & \pm 0.0211 & $27 \cdot 11$ & $25 \cdot 64-28 \cdot 58$ & $17 \cdot 60-37 \cdot 01$ \\
\hline 3 & 1.0390 & \pm 0.0032 & \pm 0.0209 & $26 \cdot 42$ & $24.96-27.89$ & $17 \cdot 03-36 \cdot 20$ \\
\hline 4 & 1.0398 & \pm 0.0032 & \pm 0.0206 & $26 \cdot 05$ & $24 \cdot 59-27 \cdot 52$ & $16 \cdot 80-35 \cdot 68$ \\
\hline Average & $1 \cdot 0381$ & \pm 0.0032 & \pm 0.0215 & 26.83 & $25 \cdot 37-28 \cdot 31$ & $17 \cdot 16-36 \cdot 92$ \\
\hline $\begin{array}{l}\text { Durnin \& Womersley } \\
(1974)^{\dagger}\end{array}$ & 1.0294 & \pm 0.0022 & \pm 0.0216 & 30.86 & $29 \cdot 84-31 \cdot 89$ & $20 \cdot 98-41 \cdot 17$ \\
\hline
\end{tabular}

* Body fat $(\%)=[(4.95 /$ density $)-4.50] \times 100($ Siri, 1956).

$\dagger$ Calculations based on their respective values for women 20-29 years of age (Durnin \& Womersley, 1974). 
proportion of individuals categorized correctly with our equations relative to those categorized correctly by the equation of Durnin \& Womersley (1974) was not statistically different (McNemar's test).

\section{DISCUSSION}

Present evidence does not indicate a requirement for prediction equations of body density from skinfold measurements specific to lactating women, despite the significant deposition of body fat during pregnancy. Regression equations generated from actual measurements made on this group could not be distinguished statistically from a previously published prediction equation derived from non-pregnant, non-lactating women(Durnin \& Womersley, 1974).

Two points germane to the application of either equations should be emphasized. The ability to predict an individual's percentage body fat from skinfold thickness is limited. The wide prediction intervals for individual observations makes this method non-discriminating. For example, one may be $95 \%$ confident that the true body fat of an individual with a predicted value of $26.83 \%$ lies between $17.16 \%$ and $36.92 \%$. Classification into broad categories did not screen individuals correctly more than $73 \%$ of the time. The accuracy of this indirect method has been assessed previously (Durnin \& Rahaman, 1967; Durnin \& Womersley, 1974) by the standard error of the estimate, which would be equivalent to a ' $67 \%$ prediction interval'. This criterion would be unacceptable for most research or clinical applications.

The arithmetical transformation of body density into percentage body fat results in an increased coefficient of variation from the change in scale and distribution of values. A small incremental change in body density can result in a change of body fat of practical consequences. For instance, a $1.0 \%$ error in body density $(1.052$ v. 1.063) caused by overestimating residual volume by 0.5 litres can result in a $4.8 \%$ difference in body fat $(15.7 \%$ v. $20.5 \%)$.

In conclusion, the use of skinfold measurements for the prediction of body fat is justified in situations when the population mean is of interest, but inaccurate when applied to individuals.

This work is the copyright of the USDA/ARS Children's Nutrition Research Center, Department of Pediatrics, Baylor College of Medicine and Texas Children's Hospital, Houston, TX.

\section{REFERENCES}

Butte, N. F., Garza, C., Stuff, J., Smith, E. O. \& Nichols, B. L. (1984). American Journal of Clinical Nutrition 39, 296-306.

Durnin, J. V. G. A. \& Rahaman, M. M. (1967). British Journal of Nutrition 21, 681-689.

Durnin, J. V. G. A. \& Womersley, J. (1974). British Journal of Nutrition 32, $77-97$.

Flint, D. J., Clegg, R. A. \& Vernin, R. G. (1980). Biochemistry 8, 369-370.

Glantz, S. A. (1981). Primer of Biostatistics, p. 261. New York: McGraw-Hill Book Co.

Hytten, F. E. \& Leitch, I. (1971). The Physiology of Human Pregnancy, 2nd ed. Oxford: Blackwell.

Katch, F. I. \& Michael, E. D. (1968). Journal of Applied Physiology 25, 92-94.

Pollock, M. L., Laughridge, E. E., Coleman, B., Linnerud, A. C. \& Jackson, A. (1975). Journal of Applied Physiology 38, 745-749.

Poo, L. J., Lew, W. \& Addis, T. (1939). Journal of Biological Chemistry 128, 69-77.

Ryan, T. R., Joiner, B. L. \& Ryan, B. F. (1981). Minitab, Version 81.1.

Seitchik, J., Alper, C. \& Szutka, A. (1963). Annals of the New York Academy of Sciences 110, 821-829.

Siri, W. E. (1956). Donner Laboratory Medical Physies Report No. 3349.

Sloan, A. W., Burt, J. J. \& Blyth, C. S. (1962). Journal of Applied Physiology 17, 967-970. 
Taggart, N., Holliday, R. M., Billewicz, W. Z., Hytten, F. E. \& Thomson, A. M. (1967). British Journal of Nutrition 21, 439-451.

Ward, G. M., Knzywicki, H. J., Rahman, D. P., Quaas, R. L., Nelson, R. A. \& Consolazio, C. F. (1975). American Journal of Clinical Nutrition 28, 162-169.

Wilmore, J. H. \& Behnke, A. R. (1970). American Journal of Clinical Nutrition 23, 267-274.

Wilmore, J. H, Vodak, P. A., Pari, R. B., Girandola, R. N. \& Billing, J. E. (1980). Medical Science Sports and Exercise 12, 216-218.

Young, C. M., Kerr Martin, M. E., Tensuan, R. \& Blondin, J. (1962). Journal of the American Dietetic Association 40, 102-107. 